DOI: 10.21767/2171-6625.100071

\title{
Effectiveness of Endoscopic Endonasal Transsphenoidal Surgery Using a Neuronavigation: Clinical Results of 178 Pituitary Adenomas
}

\section{Manabu Shirakawa1, Shinichi Yoshimura1, Kiyofumi Yamada², Tomoko lida', Kazutaka Uchida ${ }^{1}$, Yoshihiro Takada ${ }^{3}$ and Reiichi Ishikura ${ }^{4}$}

${ }^{1}$ Department of Neurosurgery, Hyogo College of Medicine, Nishinomiya city, Hyogo, Japan

${ }^{2}$ Department of Neurosurgery, Sato Daiichi Hospital, Usa city, Oita, Japan

${ }^{3}$ Department of Radiology, Meiwa Hospital, Nishinomiya city, Hyogo, Japan

${ }^{4}$ Department of Radiology, Hyogo College of Medicine, Nishinomiya city, Hyogo, Japan

Corresponding author: Shinichi Yoshimura, Department of Neurosurgery, Hyogo College of Medicine, Nishinomiya city, Hyogo, Japan. Tel: 81-798-45-6455; E-mail: s-yoshi@hyo-med.ac.jp

Received: Dec 31, 2015; Accepted: Feb 04, 2016; Published: Feb 10, 2016

\section{Abstract}

Title: Effectiveness of endoscopic endonasal transsphenoidal surgery using a neuronavigation: Clinical results of 178 pituitary adenomas

Background: The present study assesses endoscopic endonasal transsphenoidal surgery using neuronavigation for pituitary adenoma.

Methods and findings: Data were analyzed from 178 consecutive patients with pituitary adenomas who underwent endoscopic endonasal transsphenoidal surgery using neuronavigation between April 2007 and May 2014. Rates of gross total removal and overall hormone remission in patients with microadenomas were $64 \%(114 / 178)$ and $90.9 \%(30 / 32)$, respectively. However, the rate of hormonal remission was lower for macroadenomas that produce growth hormone $64.3 \%$ (9/14). The rate of complications was $2.1 \%$ (4/178) including two patients with anterior pituitary insufficiency and one each with vision deterioration and permanent diabetes insipidus.

Conclusion: Rates of complete removal and hormone remission were higher and complication rates were lower after endoscopic endonasal transsphenoidal surgery using neuronavigation to treat pituitary adenoma.

Keywords: Endoscopy; Surgical complications; Neuronavigation; Adenoma; Pituitary

Abbreviations: $\mathrm{CRH}$ : Corticotrophin-Releasing Hormone; GH: Growth Hormone; GHRP2: Growth Hormone Releasing Peptide 2; GRF: growth hormone-releasing factor; GTR: Gross Total Removal; LH-RH: Luteinizing Hormone-Releasing Hormone; OGTT: Oral Glucose Tolerance Test; PRL: Prolactin; TRH: Thyrotropin-Releasing Hormone; TSS: Transsphenoidal Surgery

\section{Introduction}

When surgically treating patients with pituitary adenoma, higher rates of removal without complications and remission of hormone abnormalities are important. Endonasal endoscopic surgery is replacing microscopic transsphenoidal surgery (TSS) that has historically been the standard approach to removing pituitary adenomas [1], as the first line procedure due to improvements in endoscope devices. By only using traditional TSS, there are some difficult cases such as conchal type of sphenoid sinus and complex septum. For such cases, recently it has been reported that neuronavigation system is useful as auxiliary method to overcome, even though the number of cases were small [2-4]. The aim of the present study was to elucidate the effectiveness of this endoscopic TSS using neuronavigation system compared to traditional endoscopic TSS.

\section{Methods}

\section{Patients}

We treated 178 pituitary adenomas in 177 patients (male, $\mathrm{n}=79$; female, $\mathrm{n}=99$; median age, $51 \mathrm{y}$; range, $15-83$ y) using endoscopic endonasal TSS with a neuronavigation system at our clinic between April 2007 and March 2014. One female patient underwent re-operation.

\section{Preoperative evaluation}

Endocrinological assessment: Levels of growth hormonereleasing factor (GRF), corticotrophin-releasing hormone $(\mathrm{CRH})$, thyrotropin-releasing hormone $(\mathrm{TRH})$, and luteinizing hormone-releasing hormone (LH-RH) were preoperatively assessed in all patients. Patients with Cushing disease underwent the 0.5-mg dexamethasone suppression test, 24-h urinary free cortisol and patients with acromegaly underwent 75-g oral glucose tolerance test (OGTT), Insulin-like growth factor-1 (IGF-1). Growth hormone releasing peptide 2 (GHRP2) levels were measured in patients with prolactinoma. 
Radiological assessment: All patients were assessed by magnetic resonance imaging (MRI) using a 1.5 or 3 Tesla MRI (Siemens Medical Solutions, Erlangen, Germany, Philips Medical Systems, Best, the Netherlands) with T1 and T2weighted spin echo with and without intravenous Magnevist contrast agent (Bayer Schering Pharma AG, $0.1 \mathrm{~mL} / \mathrm{kg}$ ). Tumor size was classified according to maximum diameter; $>10 \mathrm{~mm}$ as macroadenoma, $<10 \mathrm{~mm}$ as microadenoma, respectively [5]. The degree of cavernous sinus invasion was evaluated using the Knosp classification [6]. The paranasal sinuses of all patients were evaluated by CT before surgical planning.

\section{Surgery}

Neuronavigation system: In this study, we used CT-based navigation system to identify bony structure rather than the carotid artery because the risk of carotid injury in relatively low in the non-extended approach. Data from 1-mm CT slices were preoperatively loaded into a Stealth Station (Medtronic Inc., Minneapolis, MN, USA) navigation system. Optical and electromagnetic sensors were affixed to the forehead for optical tracking using a headband. Random input from the body surface was merged in the registration and if insufficient, point merge was added to verify the marker (Figure 1).

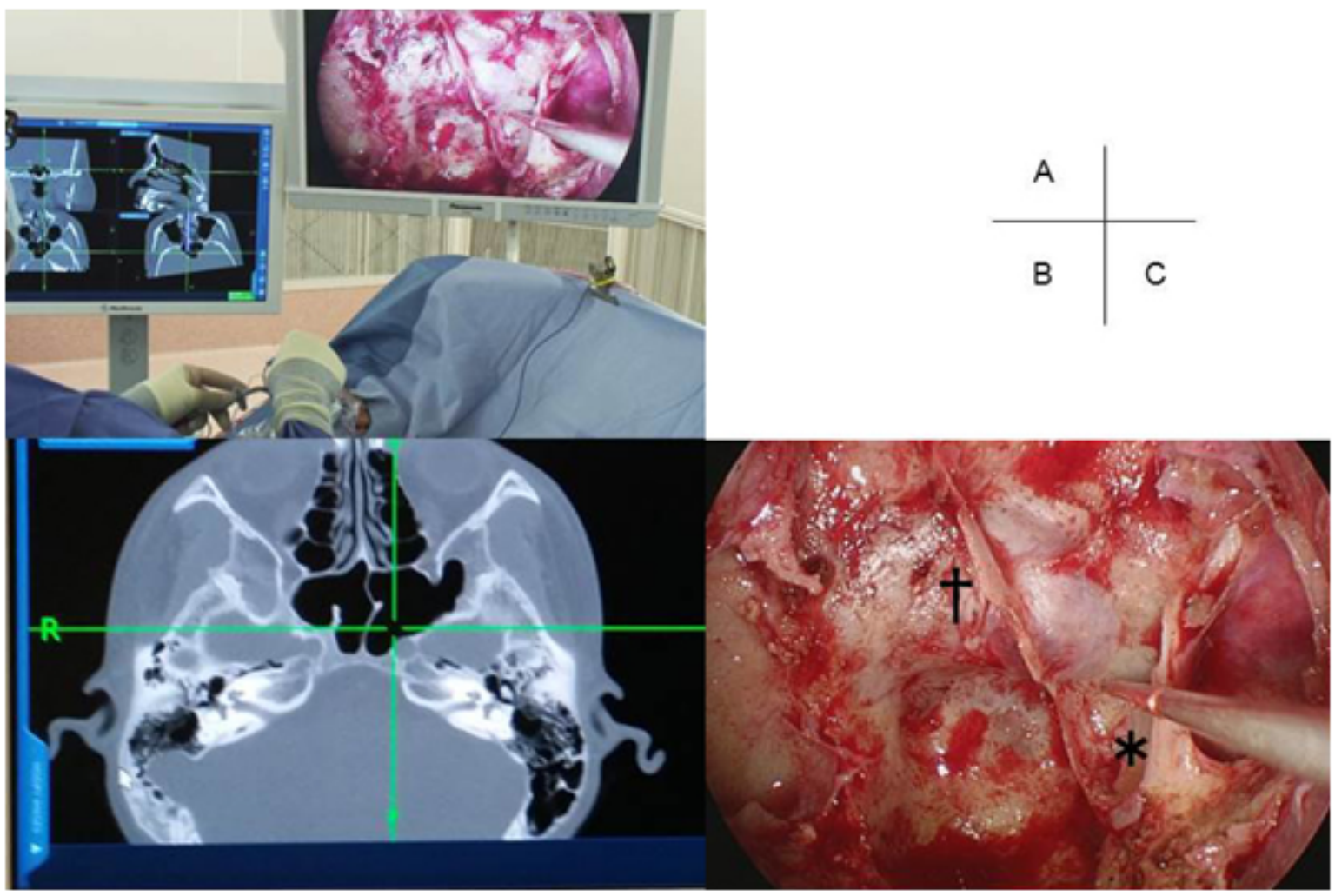

(*) Left intemal carotid artery $(\dagger)$ Sellae

Figure 1 Intraoperative view. Monitors of neuronavigation and endoscopy were set side by side during the operation

Endoscopic endonasal transsphenoidal surgery using navigation: All patients underwent endoscopic endonasal TSS, using $0-$, 30- and $70^{\circ}$ - endoscopes $(4 \mathrm{~mm})$ with Endarm (Olympus, Tokyo, Japan). Patients were placed supine under general anesthesia and the neuronavigation system was positioned. Gauze soaked in 5000-fold diluted adrenaline was inserted into both sides of the nasal cavity. We approached and cut the nasal septum mucosa via the right nostril, separated the submucosa of the nasal septum from the anterior wall of the sphenoid sinus, and drilled the wall. The left natural orifice was also drilled and expanded via bilateral nasal cavities if necessary. By using the pointer of navigation system, we detected anatomical structure of sphenoid sinus. Anterior wall of sellae was enabled to be opened widely and safety. The tumor was removed via a dural incision using a ring curette or dissector under endoscopy. Functioning adenomas were treated by extracapsular resection and non-functioning pituitary adenomas were peeled away from the normal pituitary gland under endoscopy. Thereafter, the floor of the sellae repaired in all patients using autologous bone flaps.

\section{Postoperative evaluation}

Endocrinological assessment: Hormones were evaluated six months after functioning adenoma resection. Hormonal remission in patients with Cushing's disease was defined as normal 24-h urinary free cortisol levels and $0.5 \mathrm{mg}$ dexamethasone inhibition findings $<5 \mu \mathrm{g} / \mathrm{dL}$ [7-9]. Hormonal remission in patients with acromegaly was defined as $\mathrm{GH}$ levels after OGTT $<1 \mu \mathrm{g} / \mathrm{dL}$ and restoration of IGF-I levels to normal for age and sex [10-12]. Remission of prolactinoma was defined as serum PRL $<10 \mathrm{ng} / \mathrm{mL}$ on the day after surgery [13], 
and normalized at six months after the day of surgery. Damaged anterior lobe function in patients with nonfunctioning pituitary adenoma was defined as reduced pituitary hormone levels at six months after surgery.

Radiological assessment: Two independent radiologists evaluated brain MRI images at least three months after surgery. Gross total, subtotal and partial removal was defined as the absence of residual tumor on $\mathrm{MRI},<20 \%$ and $\geq 20 \%$ remaining tumor, respectively [14].

\section{Case}

A58 year-old female was referred to our hospital with a severe headache. Brain MRI detected pituitary apoplexy and the tumor was extended to infrasellar with bone erosion. Paranasal sinuses CT showed presellar type of sphenoid sinus (Figure 2). Preoperative hormonal findings were normal. She underwent endoscopic endonasal TSS using neuronavigation at our clinic. Less pneumatization was found in sphenoid sinus. Using neuronavigation system, it enabled us to drill off the sellar widely and remove the tumor without injury of internal carotid artery. The pathological diagnosis was non-functioning adenoma. Hormone levels did not worsen after the procedure. Postoperative MRI confirmed total removal of the tumor.

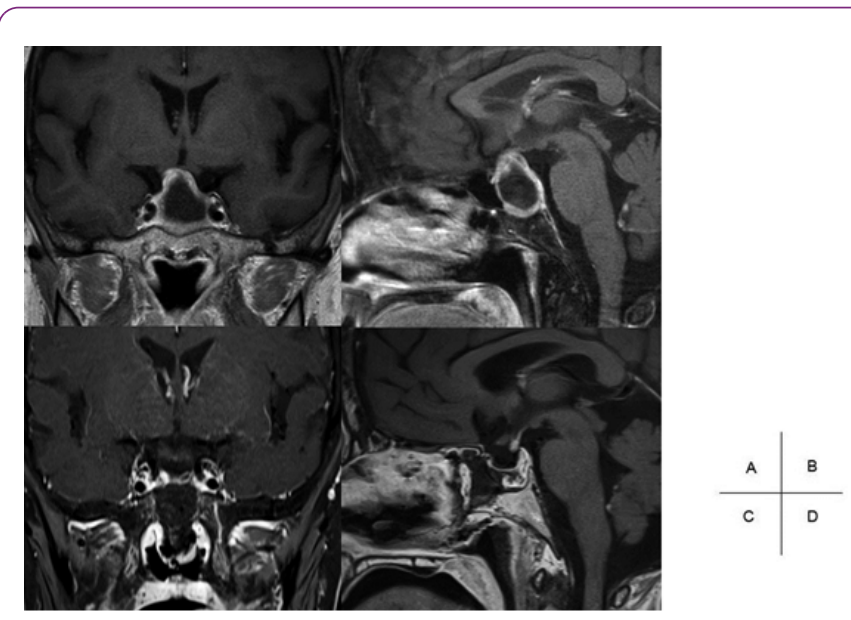

Figure 2 Pre and Post MRI. A: Pre-enhanced coronal T1 weighted image. B: pre-enhanced sagittal T1 weighted image. The tumor was located in the sellae and the suprasellae. C: Post enhanced coronal T1 weighted image. D: post enhanced sagittal T1 weighted image. The tumor was removed totally.

\section{Results}

Thirty-four and 73 patients had microadenomas and functioning adenomas, respectively. Among the adenomas, 10, 27, 11 and 25 produced ACTH (ACTHomas), GH (GHomas), TSH (TSHomas) and PRL (PRLomas), respectively (Table 1). Optical navigation system was used in 167 cases, and electromagnetic navigation system was used in 11 cases. Excellent identification of anterior wall of sellae, prominence of internal carotid artery, and tuberculum sellae was achieved in all cases.

Table 1 Patient characteristics

\begin{tabular}{|c|c|}
\hline Feature & Patients, no. \\
\hline Total no. of patients & 178 \\
\hline Male/Female & $79 / 99$ \\
\hline Prior surgery & 11 \\
\hline microadenoma & 34 \\
\hline Nonfunctioning adenoma & 105 \\
\hline Functioning adenoma & 73 \\
\hline ACTH & 10 \\
\hline $\mathrm{GH}$ & 27 \\
\hline TSH & 11 \\
\hline PRL & 25 \\
\hline \multicolumn{2}{|l|}{ Knosp grade } \\
\hline 0 & 52 \\
\hline 1 & 50 \\
\hline 2 & 33 \\
\hline 3 & 23 \\
\hline 4 & 20 \\
\hline
\end{tabular}

\section{Tumor resection}

The gross total removal (GTR) rate was $64 \%$ for all resected tumors and $97 \%$ for microadenomas. The GTR of macroadenomas with Knosp grades $0,1,2,3$ and 4 were $95.6 \%, 71.1 \%, 60.6 \%, 34.8 \%$ and $0 \%$, respectively (Table 2 ).

\section{Hormonal remission rate}

The hormonal remission in patients with microadenomas was $100 \%$ for ACTHomas and TSHomas and $90.9 \%$ (10/12) and 92.3\% (12/13) for GHomas and PRLomas, respectively (Table 3). Hormonal remission among patients with macroadenomas was $100 \%(5 / 5), 64.3 \%(9 / 14), 58.3 \%(7 / 12)$ and $37.5 \%(3 / 8)$ in ACTHomas, GHomas, PRLomas and TSHomas, respectively (Table 4).

\section{Complications}

Four (2.1\%) patients developed complications comprising anterior pituitary insufficiency $(n=2 ; 1.1 \%)$, visual deterioration $(n=1 ; 0.5 \%)$ and permanent diabetes insipidus (0.5\%; Table 5).

\section{Discussion}

Rates of tumor removal and hormone remission after endoscopic endonasal TSS using neuronavigation were similar to those of previous studies, but the complication rates were lower. The recently improved quality of endoscopic sinus 
surgery techniques and endoscopy have led to surgical outcomes that are similar to those of microscopic surgery and this has allowed endoscopic surgery to become the mainstream procedures for treating pituitary adenomas [1]. Endoscopic surgery confers the advantages of a less invasive approach to the sinuses and a brighter, wider surgical field of view compared with microscopic surgery. Variously angled endoscopes can be inserted into the sphenoid sinus, tumors can be removed under direct view and wider sellae lesions can be visualized by endoscopic, than by microscopic surgery [15]. However, we found that the cases of conchal type or presellar type of sphenoid sinus and the cases of complex septum were difficult to drill off its bony structures using only endoscopic system, as well as microscopic surgery. We have recently applied endoscopic TSS using navigation. Although experience with endoscopic endonasal TSS using neuronavigation has been reported [2], the effectiveness of the method has not been documented. Therefore, we determined the applicability of endoscopic endonasal TSS using neuronavigation in 178 pituitary adenomas.

\section{Removal rate}

The GTR rate for all tumors and for microadenomas were $64 \%$ and $97 \%$ (33/34 tumors), respectively. One residual tumor was located only in the cavernous sinus. On the other hand, macroadenomas with Knosp grades 0 to 3 were principally resected. However, most macroadenomas with Knosp grade 4 could not be completely removed because the tumor body had extended laterally in most of them (Table 2). Jackson et al reported a GTR rate of $79.3 \%$ and a removal rate including subtotal resection of $89 \%$ under traditional TSS [16]. Our removal rate including subtotal resection was $82 \%$. Comparable GTR rate can be obtained by endoscopic endonasal TSS using neuronavigation compared with traditional TSS.

Table 2 Tumor removal rate

\begin{tabular}{|c|c|c|c|}
\hline Tumor type & No of operations & Gross total removal rate (\%) & $\begin{array}{l}\text { Gross total + subtotal removal rate } \\
(\%)\end{array}$ \\
\hline Total & 178 & $114(64)$ & $146(82)$ \\
\hline Microadenoma & 34 & $33(97)$ & $33(97)$ \\
\hline Macroadenoma & 144 & $81(56.2)$ & $113(78.4)$ \\
\hline \multicolumn{4}{|l|}{ Knosp grade } \\
\hline 0 & 23 & $22(95.6)$ & $22(95.6)$ \\
\hline 1 & 45 & $32(71.1)$ & $43(95.6)$ \\
\hline 2 & 33 & $20(60.6)$ & $29(87.9)$ \\
\hline 3 & 23 & $8(34.8)$ & $16(69.6)$ \\
\hline 4 & 20 & $0(0)$ & $3(15)$ \\
\hline
\end{tabular}

Table 3 Hormonal remission rate (microadenoma)

\begin{tabular}{|l|l|l|}
\hline Hormone type & Patients, No & Remission rate (\%) \\
\hline Total & 32 & $30(90.9)$ \\
\hline ACTH & 5 & $5(100)$ \\
\hline GH & 11 & $10(90.9)$ \\
\hline PRL & 13 & $12(92.3)$ \\
\hline TSH & 3 & $3(100)$ \\
\hline
\end{tabular}

\section{Hormonal remission rate}

The hormonal remission rate was $\geq 90 \%$ for microadenomas, whereas that for macroadenomas was lower. The rates for GHomas and PRLomas were similar and that for TSHomas was the lowest. The remission rates for ACTHomas reported by Dimopoulou et al [9] and for GHomas reported by Jane et al [10] were $69 \%$ and $60.9 \%$, respectively. Our results were similar to these findings.
All patients with ACTHomas went into complete hormone remission after resection, possibly because of a relationship with Knosp grades 0-2 that were relatively low, whereas the Knosp grades of half of the GHomas were $3-4$, which was relatively high.

Table 4 Surgical remission rate (macroadenoma)

\begin{tabular}{|l|l|l|}
\hline Hormone type & Patients, No & Remission rate (\%) \\
\hline Total & 39 & $24(61.5)$ \\
\hline ACTH & 5 & $5(100)$ \\
\hline GH & 14 & $9(64.3)$ \\
\hline PRL & 12 & $7(58.3)$ \\
\hline TSH & 8 & $3(37.5)$ \\
\hline
\end{tabular}

\section{Complications}

Our total complication rate was $2.1 \%$, and did not include major perioperative complications such as death or damage to the carotid artery. The reported complication rates of TSS are 
9.1\%, $23.4 \%$ and $22.1 \%[1,14,16]$, which are far higher than ours. Damage to the carotid artery leads to serious complications (Table 6). Cappabianca et al and Gondim et al reported carotid artery injury rates of $0.7 \%-0.9 \%[14,16]$. Preventing such damage might thus be one advantage of endoscopic TSS with navigation [17].

One report has indicated CSF leakage in $3.5 \%$ of patients who underwent traditional TSS [18]. However, none of our patients developed serious CSF leakage. We used the navigation system as much as possible after opening the sellae floor and better visibility enabled appropriate and straightforward repair of the sellae.

\section{Advantages of using navigation system}

There are several advantages of navigation system. First, it can identify the bony anatomical structure of the sphenoidal sinus cavity, which enables to create sellae floor bone window safely and widely $[19,20]$, without any injuries of internal carotid artery. Therefore, CT-based navigation system was applied in this study. Second, one of other advantages is that the system can confirm the relationship between tumor and around structure timely and precisely. Thus, the tumor can be removed more safely. Those above advantages may have led our good results, which removal rate was same to traditional TSS with less complications, in this study.

\section{Limitation}

We reported the effectiveness of endoscopic TSS using neuronavigation system for pituitary adenoma in this study.
However, our study may have a selection bias because the patients suitable for endoscopic approach might be selectively introduced to our hospital. Therefore, challenging cases like giant pituitary adenoma was not included in this study. Also, this was a retrospective, single-center analysis and the number of patients was relatively small. Therefore, a comparison with standard microscopic approach in a prospective fashion with a large number of patients might be necessary to determine the real effect of endoscopic TSS using neuronavigation in the future.

Table 5 Surgical complications

\begin{tabular}{|l|c|c|}
\hline Complications analysis & Number of patients & Rate (\%) \\
\hline Anterior pituitary insufficiency & 2 & $1.1 \%$ \\
\hline Vision deterioration & 1 & $0.5 \%$ \\
\hline Cerebrospinal fluid leak & 0 & $0 \%$ \\
\hline Permanent diabetes insipidus & 1 & $0.5 \%$ \\
\hline Meningitis & 0 & $0 \%$ \\
\hline Post operative hematoma & 0 & $0 \%$ \\
\hline Carotid artery injury & 0 & $0 \%$ \\
\hline Death & 0 & $0 \%$ \\
\hline Opthalmoplegia & 0 & $0 \%$ \\
\hline Total & 4 & $2.1 \%$ \\
\hline
\end{tabular}

Table 6 Comparison of complication between published series

\begin{tabular}{|c|c|c|c|c|c|c|c|c|c|c|}
\hline & year & cases & $\begin{array}{l}\text { Total } \\
()\end{array}$ & $\begin{array}{l}\text { CSF } \\
\text { leakage } \\
()\end{array}$ & Meningitis () & $\begin{array}{l}\text { Cranial nerve } \\
\text { disturbance () }\end{array}$ & $\begin{array}{l}\text { Injury } \\
\text { of ICA } \\
()\end{array}$ & $\begin{array}{l}\text { Hemorrhagic } \\
\text { complication } \\
\text { () }\end{array}$ & $\begin{array}{l}\text { DI } \\
()\end{array}$ & $\begin{array}{l}\text { Pituitary } \\
\text { dysfunction () }\end{array}$ \\
\hline Helene, et al & $\begin{array}{l}2002-2 \\
011\end{array}$ & 506 & 9.1 & 4.7 & 2 & 2 & 0.4 & 1.2 & - & - \\
\hline Dehdashti, et al & $\begin{array}{l}2004-2 \\
007\end{array}$ & 200 & 9 & 3.5 & 1 & 0 & 0 & 0.5 & 1 & 3 \\
\hline Gondim J A, et al & $\begin{array}{l}1998-2 \\
009\end{array}$ & 301 & 23.4 & 2.6 & 0.6 & 0.3 & 0.9 & 0.3 & 6.3 & 11.6 \\
\hline $\begin{array}{l}\text { Cappabianca, et } \\
\text { al }\end{array}$ & $\begin{array}{l}1997-2 \\
001\end{array}$ & 146 & 22.1 & 2.1 & 0.7 & 0.7 & 0.7 & 0.7 & 3.5 & 13.7 \\
\hline Present study & $\begin{array}{l}2007-2 \\
013\end{array}$ & 178 & 2.1 & 0 & 0 & 0.5 & 0 & 0 & 0.5 & 1.1 \\
\hline
\end{tabular}

\section{Conclusion}

The outcomes are favorable and complication rates are lower after surgical treatment of pituitary adenomas using endoscopic endonasal TSS with navigation.

\section{Conflicts of Interest Disclosure}

None of the authors has any conflicts of interest to disclose.

\section{References}

1. Halvorsen H, Ramm-Pettersen J, Josefsen R, Rønning P, Reinlie S, et al. (2014) Surgical complications after transsphenoidal microscopic and endoscopic surgery for pituitary adenoma: a consecutive series of 506 procedures. Acta Neurochir (Wien) 156: 441-449.

2. Eboli P, Shafa B, Mayberg M (2011) Intraoperative computed tomography registration and electromagnetic neuronavigation 
for transsphenoidal pituitary surgery: accuracy and time effectiveness. J Neurosurg 114: 329-335.

3. Yang S, Zhang C, Zhu T, Cai L, Gao S, et al. (2007) Resection of gliomas using positron emission tomography/computed tomography neuronavigation. Neurol Med Chir (Tokyo) 47: 397-401.

4. Zhao Y, Yu S, Wang R, Zhao J (2006) Clinical application of a neuronavigation system in transsphenoidal surgery of pituitary macroadenoma. Neurosurg Rev 29: 306-311

5. De Souza B, Brunetti A, Fulham MJ, Brooks RA, DeMichele D, et al. (1990) Pituitary microadenomas: a PET study. Radiology 177: 39-44.

6. Knosp E, Steiner E, Kitz K, Matula C (1993) Pituitary adenomas with invasion of the cavernous sinus space: a magnetic resonance imaging classification compared with surgical findings. Neurosurgery 33: 610-617.

7. Berker M, Işikay I, Berker D, Bayraktar M, Gürlek A (2013) Early promising results for the endoscopic surgical treatment of Cushing's disease. Neurosurg Rev 15 [Epub ahead of print].

8. Alahmadi H, Cusimano MD, Woo K, Mohammed AA, Goguen J, et al. (2013) Impact of technique on cushing disease outcome using strict remission criteria. Can J Neurol Sci 40: 334-341.

9. Dimopoulou C, Schopohl J, Rachinger W, Buchfelder M, Honegger J, et al. (2013) Long-term remission and recurrence rates after first and second transsphenoidal surgery for Cushing's disease: care reality in the Munich Metropolitan Region. Eur J Endocrinol 21: 283-292.

10. Jane JA Jr, Starke RM, Elzoghby MA, Reames DL, Payne SC, et al. (2011) Endoscopic transsphenoidal surgery for acromegaly:remission using modern criteria, complications, and predictors of outcome. J Clin Endocrinol Metab 96: 2732-2740.

11. Kim EH, Oh MC, Lee EJ, Kim SH (2012) Predicting long-term remission by measuring immediate postoperative growth hormone levels and oral glucose tolerance test in acromegaly. Neurosurgery 70: 1106-1113.

12. Shanik MH (2016) Limitations of current approaches for the treatment of Acromegaly. Endocr Pract 22: 210-219.

13. Amar AP, Couldwell WT, Chen JC, Weiss MH (2002) Predictive value of serum prolactin levels measured immediately after transsphenoidal surgery. J Neurosurg 97: 307-314.

14. Cappabianca P, Cavallo LM, Colao A, de Divitiis E (2002) Surgical complications associated with the endoscopic endonasal transsphenoidal approach for pituitary adenomas. J Neurosurg 97: 293-298.

15. Saeki N, Horiguchi K, Murai H, Hasegawa $Y$, Hanazawa $T$, et al. (2010) Endoscopic endonasal pituitary and skull base surgery. Neurol Med Chir (Tokyo) 50: 756-764.

16. Gondim JA, Almeida JP, Albuquerque LA, Schops M, Gomes E, et al. (2011) Endoscopic endonasal approach for pituitary adenoma: surgical complications in 301 patients. Pituitary 14: 174-183.

17. Dehdashti AR, Ganna A, Karabatsou K, Gentili F (2008) Pure endoscopic endonasal approach for pituitary adenomas: early surgical results in 200 patients and comparison with previous microsurgical series. Neurosurgery 62: 1006-1015.

18. Zhan R, Ma Z, Wang D, Li X (2015) Pure Endoscopic Endonasal Transsphenoidal Approach for Nonfunctioning Pituitary Adenomas in the Elderly: Surgical Outcomes and Complications in 158 Patients. World Neurosurg 84: 1572-1578

19. Mert A, Micko A, Donat M, Maringer M, Buehler K, et al. (2014) An advanced navigation protocol for endoscopic transsphenoidal surgery. World Neurosurg 82: S95-105.

20. Yano S, Hide T, Shinojima N, Hasegawa Y, Kawano T, et al. (2014) Endoscopic endonasal skull base approach for parasellar lesions: Initial experiences, results, efficacy, and complications. Surg Neurol Int 16: 51. 